\section{PERIPHERALLY INSERTED CENTRAL VENOUS CATHETERS IN NEONATE: A QUICK AND EFFICIENT STANDARDIZED TECHNIQUE}

doi:10.1136/archdischild-2012-302724.1198

S Breinig, S Pelluau, K Laganthe, MC Granier, M Gineste, C Alberge, MC Bloom, MO Marcoux. Intensive Care Unit, Hopital des Enfants, Toulouse, France

Background and Aims Peripherally inserted central venous catheters (PICCs) are commonly used for neonatal vascular access. Early catheter-related sepsis and catheter non infectious complications are linked with initial dressing method. We evaluate efficacy of our specific PICCs insertion protocol with trained nurses and doctors.

Methods We observed prospectively 1686 PICC procedures in neonate (0-28d) from 2002 to 2011. Silicon PICCs were inserted from 0 to 28 days corrected age. Procedure followed our specific protocol. Results 1686 PICCs were attempted with a success rate of $96.2 \%$ in neonates with a mean gestational age of 29.7 weeks at a median age of $3(0-94 \mathrm{~d})$ days of life.

In the successful PICCs, median number of venous puncture was 1 (1-13), median time spent was 20 (5-120) minutes, device change in $11.7 \%$ and site change in $5.9 \%$. Median temperature difference between the beginning and the end of the procedure was very low: $-0.2^{\circ} \mathrm{C}$ ( -1.5 to 1.8$) .187$ complications (11.5\%) occurred: 105 diffusions of which 6 pericardic effusions, 25 occlusions, 37 porous catheters, 7 surrounding catheter tissue inflammations. 13 PICCs were removed for infection (sepsis or local mycosis).

Conclusions Standardized protocol with specific nurse and doctor leads to a success rate of $96.2 \%$ with a small time spent for insertion and a median of one attempt mostly in the initial chosen site. This quick method leads to low neonate cooling and expose patients to minimal infection risk and complications.

\section{METABOLIC RISK FACTORS AND PROGNOSIS IN CHILDREN WITH UROLITHIASIS}

doi:10.1136/archdischild-2012-302724.1199

${ }^{1} \mathrm{~S}$ Yüksel, ${ }^{2} \mathrm{H}$ Tancer Elçi, ${ }^{3} \mathrm{~T}$ Ince Becerir, ${ }^{2} \mathrm{M}$ Deniz, ${ }^{4} \mathrm{~A}$ Koçyiğit, ${ }^{5} \mathrm{~A}$ Ergin. ${ }^{1}$ Pediadric Nephrology; ${ }^{2}$ Pediatrics; ${ }^{3}$ Pediatric Nephrology; ${ }^{4}$ Radiodiagnostics; ${ }^{5}$ Public Health Pamukkale University, Faculty of Medicine, Denizli, Turkey

Objective To investigate the demographic characteristics, clinical features, and metabolic risk factors of children with urolithiasis.

Methods This retrospective study enrolled 52 boys, 51 girls with urolithiasis diagnosed by ultrasonography. Mean age at presentation was 60(1-192) months, and mean follow-up period was 5.5 (1-27)months.

Results The most common symptom was restlessness in infants (<1year), while it was abdominal or flank pain in older children $(p<0.001)$. Microcalculi (stone diameter $<3 \mathrm{~mm})$ and calculi $(>3 \mathrm{~mm})$ were found in $26 \%$ and in $74 \%$ of patients, respectively. Hypercalciuria was the most common abnormality, followed by hypomagnesiuria (Table 1). Recurrent urinary tract infection (UTI) was detected in half of the patients. Four patients underwent ESWL, five underwent open surgery, and the other 94 were treated with conservative therapies. Spontaneous passage occurred in 19 patients. Stone analysis revealed calcium-oxalate in $85 \%$. At the time of their last visit, in $70 \%$ of the patients with conservative therapies, the stones were disappeared or diminished in size by appropriate therapy such as water intake, diet, hydrochlorothiazide and potassium-citrate.

Conclusion Identifying the underlying metabolic risk factor is important in order to choose the appropriate treatment modality, prevent stone recurrence and renal damage. Patients presenting with restlessness, especially infants must be evaluated in terms of renal stone disease by ultrasonography.

\section{THE CORRELATION BETWEEN RENAL DAMAGE AND CLINICAL AND LABORATORY FINDINGS IN CHILDREN WITH ACUTE PYELONEPHRITIS}

doi:10.1136/archdischild-2012-302724.1200

${ }^{1} \mathrm{~S}$ Yüksel, ${ }^{2} \mathrm{~B}$ Seyhan, ${ }^{1} \mathrm{~T}$ Becerir, ${ }^{3} \mathrm{~A}$ Koçyiğit, ${ }^{4} \mathrm{D}$ Yüksel. 'Department of Pediatric Nephrology, Pamukkale University School of Medicine; 'Tavas State Hospital ${ }^{3}$ Department of Radiodiagnostic; ${ }^{4}$ Department of Nuclear Medicine, Pamukkale University School of Medicine, Denizli, Turkey

Objective The aim of this study was to determine the risk factors such as age, sex, duration of fever, voiding dysfunction, constipation, history of recurrent UTI, the levels of C-reactive protein (CRP), erythrocyte sedimentation rate (ESR), white blood cell (WBC), polymorphonuclear leukocytes (PNL), platelet count, mean platelet volume $(M P V)$, serum urea, creatinine, proteinuria, type of microorganisms, presence of vesicoureteral reflux(VUR) for the development of renal damage in patients with acute pyelonephritis

Material and Methods A total of 197 children (44 boys, 153 girls) were enrolled in the study, mean age was $4.7 \pm 4.0$ years ( 1 month-16 years). Ultrasonography, renal cortical scintigraphy (RCS) with ${ }_{99 \mathrm{~m}} \mathrm{Tc}$-Dimercaptosuccinic acid and voiding cystourethrography were performed in all patients. The patients were grouped by age according to presumed risk of renal damage: high risk( $\leq 1$ year), moderate risk( $1-5$ years), and low risk ( $>5$ years).

Results Renal lesions on RCS were detected in 91 patients. Abnormal RCS were found in 35\% of infants younger than 1 year, in $57 \%$ of children between 1-5 years and in $42 \%$ of children older than 5 years. Abnormal RCS was found in $66 \%$ of the children with VUR and in $42.7 \%$ of those without VUR $(p=0.005)$. There was a significant positive correlation between abnormal RCS and VUR, duration of fever ( $>2$ days), history of recurrent UTI, high levels of ESR, CRP, WBC, and PNL at the presentation.

Conclusion The patients with VUR were 2.6 times more likely to have renal damage. The risk of renal damage should be considered in all age groups.

\section{WHOLE EXON DELETION IN THE CLAUDIN 16 GENE, A NOVEL MUTATION IN FAMILIAL HYPOMAGNESEMIA/ HYPERCALCIURIA/NEPHROCALCINOSIS (FHHNC) AND SENSORINEURAL DEAFNESS (SND)}

doi:10.1136/archdischild-2012-302724.1201

${ }^{1}$ SA Sanjad, ${ }^{2} \mathrm{Y}$ Lu, ${ }^{1,3} \mathrm{C}$ Khoury, ${ }^{4} \mathrm{Z}$ Habbal, ${ }^{2} \mathrm{R}$ Lifton, Family with FHHNCS AND. ${ }^{1}$ Pediatrics, American University of Beirut Medical Center, Beirut, Lebanon; ${ }^{2}$ Genetics, Yale University School of Medicine, New Haven, CT; 3/nternal Medicine, Northwestern University, Chicago, IL, USA; ${ }^{4}$ Pathology, American University of Beirut Medical Center, Beirut, Lebanon

Abstract 1199 Table 1 Urine metabolic analysis

\begin{tabular}{|c|c|c|c|c|c|c|c|}
\hline Risk factor & Patients(\%) & Risk factor & Patients(\%) & Risk factor & Patients(\%) & Risk factor & Patients(\%) \\
\hline Hypercalciuria & $32(31.1)$ & Cystinuria & $4(3.9)$ & Hyperoxaluria & $2(1.9)$ & Hypercalciuria+hypernatriuria & $2(1.9)$ \\
\hline Hypomagnesuria & $13(12.6)$ & Hyperuricosuria & $3(2.9)$ & Hypercalciuria+hypocitraturia & $4(3.9)$ & Hypocitraturia+hypomagnesuria & $2(1.9)$ \\
\hline Hypernatriuria & $11(10.7)$ & Hypocitraturia & $3(2.9)$ & Hypercalciuria+hyperoxaluria & $3(2.9)$ & Normal & $24(23.3)$ \\
\hline
\end{tabular}

